\title{
Abstract \\ Regolith as Baseline to a Future Space Farm ${ }^{\dagger}$
}

\author{
Luigi Giuseppe Duri ${ }^{1, *}$, Antonio Giandonato Caporale ${ }^{1}\left(\mathbb{D}\right.$, Paola Adamo $^{1,2}$ (D) and Youssef Rouphael ${ }^{1, *}$ (D) \\ 1 Department of Agricultural Sciences, Via Università 100, 80055 Portici, Italy; ag.caporale@unina.it (A.G.C.); \\ paola.adamo@unina.it (P.A.) \\ 2 Interdepartmental Research Centre on the 'Earth Critical Zone' for Supporting the Landscape and \\ Agroenvironment Management (CRISP), University of Naples Federico II, 80055 Portici, Italy \\ * Correspondence: luigigiuseppe.duri@unina.it (L.G.D.); youssef.rouphael@unina.it (Y.R.) \\ + Presented at the 1st International Electronic Conference on Agronomy, 3-17 May 2021; Available online: \\ https://iecag2021.sciforum.net/.
}

check for

updates

Citation: Duri, L.G.; Caporale, A.G.; Adamo, P.; Rouphael, Y. Regolith as Baseline to a Future Space Farm. Biol. Life Sci. Forum 2021, 3, 15. https:// doi.org/10.3390/IECAG2021-09702

Academic Editor: Cornelia Rumpel

Published: 1 May 2021

Publisher's Note: MDPI stays neutral with regard to jurisdictional claims in published maps and institutional affiliations.

Copyright: (C) 2021 by the authors. Licensee MDPI, Basel, Switzerland. This article is an open access article distributed under the terms and conditions of the Creative Commons Attribution (CC BY) license (https:// creativecommons.org/licenses/by/ $4.0 /)$.
Abstract: In the last decade, a great deal of attention has been paid and many resources have been invested in space colonization. Indeed, many space agencies, perhaps most notably NASA (National Aeronautics and Space Administration), have created programs that aim to establish a stable settlement on the Moon (ideally in the next few years), with additional future goals of a conducting the first manned mission to Mars. Bioregenerative Life-Support Systems (BLSS) will play a key role in these endeavors because it is unrealistic and incredibly difficult to provide all of the consumables that are necessary to keep the crew members on these missions alive due high production costs and the amount of planning that is required to ensure that these products maintain their quality. An alternative solution that can reduce the associated costs and that can support delivery can be provided through the implementation of BLSS with in situ resource utilization (ISRU). Specifically, this technology aims to improve the use of the regolith (the "soil" of a planet or a satellite) on the Moon and on Mars and to promote the re-use of the waste materials that are produced either during the journey or while living in these future colonies, such as human excreta and food residues. At present, little research has investigated the feasibility of use of these resources for crop production or the effects of these resources on crop yield and nutritional quality. Our work aims to fill this gap by using regolith simulants that have been mixed at different rates $(0 \%, 30 \%$ or $50 \%)$ with a monogastric manure that has been sieved to $2 \mathrm{~mm}$ as plant growth substrates to evaluate their long-term effects on lettuce (Lactuca sativa L.). No synthetic fertilizers were delivered to the plants during the entire cultivation period, and the specimens were only provided deionized water. Our results show that the germination rate was around $97 \%$ under pure simulant conditions, whereas germination was inhibited in the substrates that contained the monogastric manure. Figure 1 shows the effects of monogastric manure, which was demonstrated to improve the fresh yield by $23 \%$ and $17 \%$ for the $30 \%$ and $50 \%$ of amendment treatments, respectively, compared to pure simulant.

Keywords: ISRU; lettuce; regolith simulant; Lactuca sativa L.

Supplementary Materials: The poster presentation is available online at https:/ /www.mdpi.com/ article/10.3390/IECAG2021-09702/s1. 